\title{
Development of an Electromagnetic Wave Shielding Textile by Electroless Ni-Based Alloy Plating
}

\author{
Makoto Sonehara $^{1}$, Shin Noguchi ${ }^{2}$, Tadashi Kurashina ${ }^{2}$, Toshiro Sato ${ }^{1}$, Kiyohito Yamasawa ${ }^{1}$, and \\ Yoshimasa Miura ${ }^{1}$, Fellow, IEEE \\ ${ }^{1}$ Spin Device Technology Center, Shinshu University, Nagano, 380-8553 Japan \\ ${ }^{2}$ Yamato Denki Ind. Co., Ltd. Suwa Plant, Suwa, 392-0015 Japan
}

\begin{abstract}
A polyester nonwoven textile with Ni-based alloy coating was fabricated, and the effect of electromagnetic wave shielding was evaluated. The Ni-based was coated by electroless plating on the textile. The electromagnetic wave shielding effect of the textile with Ni-B coating was about $99.98 \%$ over the induction range of 6-13 GHz. Because the textile has thin, light, flexible, and breathable characteristics, it will be versatile for the various electromagnetic wave shielding applications.
\end{abstract}

Index Terms-Electroless palting, electromagnetic wave shielding, metallic magnetic material, Ni-based alloy, polyester nonwoven textile.

\section{INTRODUCTION}

$\mathbf{E}$ LECTROMAGNETIC interference (EMI) has become extremely serious in various electronic equipment such as personal computers (a few gigahertz), cellular phones $(0.8-2 \mathrm{GHz})$, and others. Not only the noise of the fundamental frequency but also the noises of the harmonic high frequency in the equipment or the system must be removed. Therefore, it is necessary to develop a wideband noise suppressor sheet for the EMI measures [1].

The authors developed a textile with the metallic magnetic material which was Ni-Fe coating by sputtering unit. The textile was lighter than the noise suppressor sheet, and it was flexible and breathable. And the electromagnetic wave shielding effect of the textile was about $90 \%$ from 1 to $13 \mathrm{GHz}$ [2]. However, the Ni-Fe was hard to be coated to the inside of the textile, so then it was difficult to obtain a higher electromagnetic wave shielding effect. Therefore, an electroless plating was used to coat the metallic magnetic material inside the textile. This paper describes the development of an electromagnetic wave shielding textile by electroless Ni-based alloy plating.

\section{FABRICATION}

The textile used here was the polyester nonwoven textile (Kurabo Industries) with a weight of $60 \mathrm{~g} / \mathrm{m}^{2}$, a thickness of $210 \mu \mathrm{m}$, and a mean fiber diameter of $40 \mu \mathrm{m}$.

First, the textile was given the pretreatment for the electroless plating as described in Table I. Then, the metallic magnetic material, Ni-based alloy, was coated on the textile with the electroless plating as shown Fig. 1. The electroless plating conditions are shown in Table II.

\section{MEASUREMENT}

The imaginary part of permeability was measured using a thin-film permeameter (Ryowa Denshi; PMM-9G1) [3].

Manuscript received March 05, 2009. Current version published September 18, 2009. Corresponding author: M. Sonehara (e-mail: makoto@ shinshu-u.ac. jp).

Digital Object Identifier 10.1109/TMAG.2009.2021403
TABLE I

Pretreatment Conditions for EleCtroless Ni-BASEd Alloy Plating

\begin{tabular}{|c|c|c|}
\hline Process & Temperature $\left[{ }^{\circ} \mathrm{C}\right]$ & Time $[\mathrm{min}]$ \\
\hline 1. Alkaline degreasing & 50 & 5 \\
\hline 2. Alkaline washing & 50 & 5 \\
\hline 3. Acid neutralization & 40 & 4 \\
\hline 4. Etching & 25 & 5 \\
\hline 5. Conditioning & 25 & 5 \\
\hline 6. Pd catalyzing & 25 & 5 \\
\hline
\end{tabular}

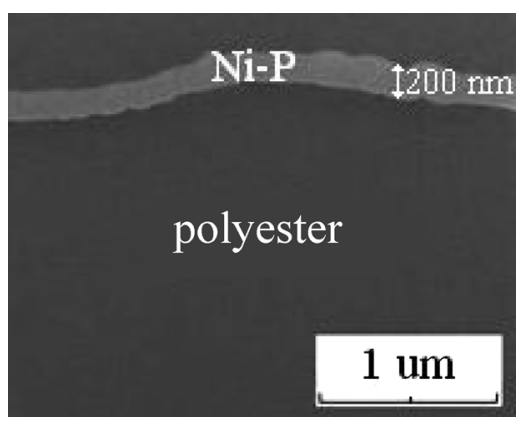

Fig. 1. Typical SEM image of the shielding textile sample Ni- $P_{\mathrm{M}}$.

TABLE II

Electroless Plating CONDITIONS OF Ni-BASEd Alloy

\begin{tabular}{|c|c|c|c|}
\hline Sample name & $\mathrm{Ni}-\mathrm{P}_{\mathrm{M}}$ & $\mathrm{Ni-P_{L }}$ & $\mathrm{Ni}-\mathrm{B}$ \\
\hline Additive & $\mathrm{P}$ & $\mathrm{P}$ & $\mathrm{B}$ \\
\hline $\begin{array}{c}\text { Average composition } \\
\text { of electroless plating film [wt.\%] }\end{array}$ & $\mathrm{Ni}_{9_{2 .} .5} \mathrm{P}_{7.5}$ & $\mathrm{Ni}_{9} \mathrm{P}_{2}$ & $\mathrm{Ni}_{9.9 .8} \mathrm{~B}_{0.2}$ \\
\hline Bath temperature $\left[{ }^{\circ} \mathrm{C}\right]$ & 80 & 90 & 65 \\
\hline $\mathrm{pH}$ & 4.6 & 6.5 & 6.7 \\
\hline $\mathrm{Ni}$ density $[\mathrm{g} / \mathrm{L}]$ & 5.0 & 5.5 & 6.7 \\
\hline Coating ratio $[\mathrm{nm} / \mathrm{s}]$ & 2.8 & 5.6 & 1.4 \\
\hline Reductant & $\begin{array}{l}\text { Hypophosphorus } \\
\text { acid }\end{array}$ & $\begin{array}{l}\text { Hypophosphorus } \\
\text { acid }\end{array}$ & $\begin{array}{c}\text { Dimetil- } \\
\text { aminobenzaldehído }\end{array}$ \\
\hline
\end{tabular}

The electromagnetic wave shielding effect defined as SE in the nanofiber shielding textile was measured using a vector network analyzer, an S-parameter test set, and the waveguide components in Fig. 2. The nanofiber shielding nonwoven textile 


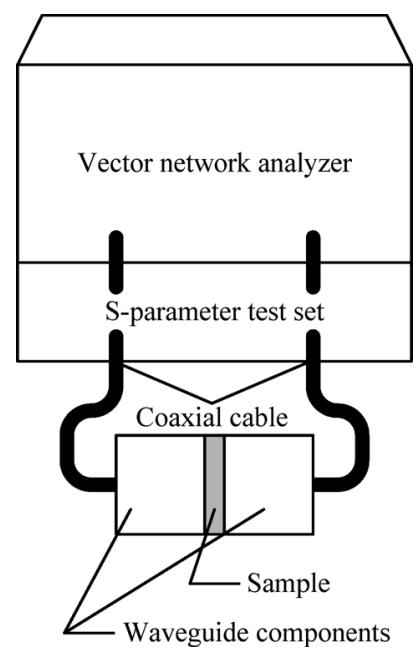

Fig. 2. Schematic of the measurement system for the electromagnetic wave shielding effect.

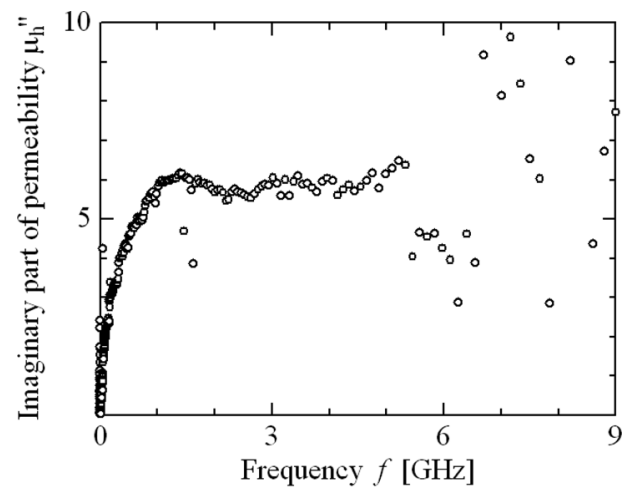

Fig. 3. Frequency dependence of the imaginary part of permeability measured for the sample Ni-B.

sandwiched between the waveguide components was connected to the S-parameter test set.

$\mathrm{SE}\left(=1-P_{\text {thru }} / P_{\text {in }}\right)$ was calculated with the following equation [4]:

$$
\begin{aligned}
\mathrm{SE} & =\left(P_{\text {ref }}+P_{\text {loss }}\right) / P_{\text {in }}=1-P_{\text {thru }} / P_{\text {in }} \\
& =1-10^{\left(S_{21}[\mathrm{~dB}] / 10\right)}
\end{aligned}
$$

where $P_{\text {ref }}$ is the reflective power, $P_{\text {loss }}$ is the loss power, $P_{\text {in }}$ is the input power, $P_{\text {thru }}$ is the through power, and $S_{21}$ is the forward transmission coefficient. $S_{21}$ for the nanofiber shielding textile was obtained by the vector network analyzer and the S-parameter test set, and $P_{\text {ref }} / P_{\text {in }}$ and $P_{\text {loss }} / P_{\text {in }}$ were calculated with the following equations:

$$
\begin{aligned}
P_{\text {ref }} / P_{\text {in }} & =10^{\left(S_{11}[\mathrm{~dB}] / 10\right)} \\
P_{\text {loss }} / P_{\text {in }} & =1-\left(10^{\left(S_{11}[\mathrm{~dB}] / 10\right)}+10^{\left(S_{21}[\mathrm{~dB}] / 10\right)}\right)
\end{aligned}
$$

where $S_{11}$ is the input reflection coefficient, which was obtained by the vector network analyzer and the S-parameter test set.
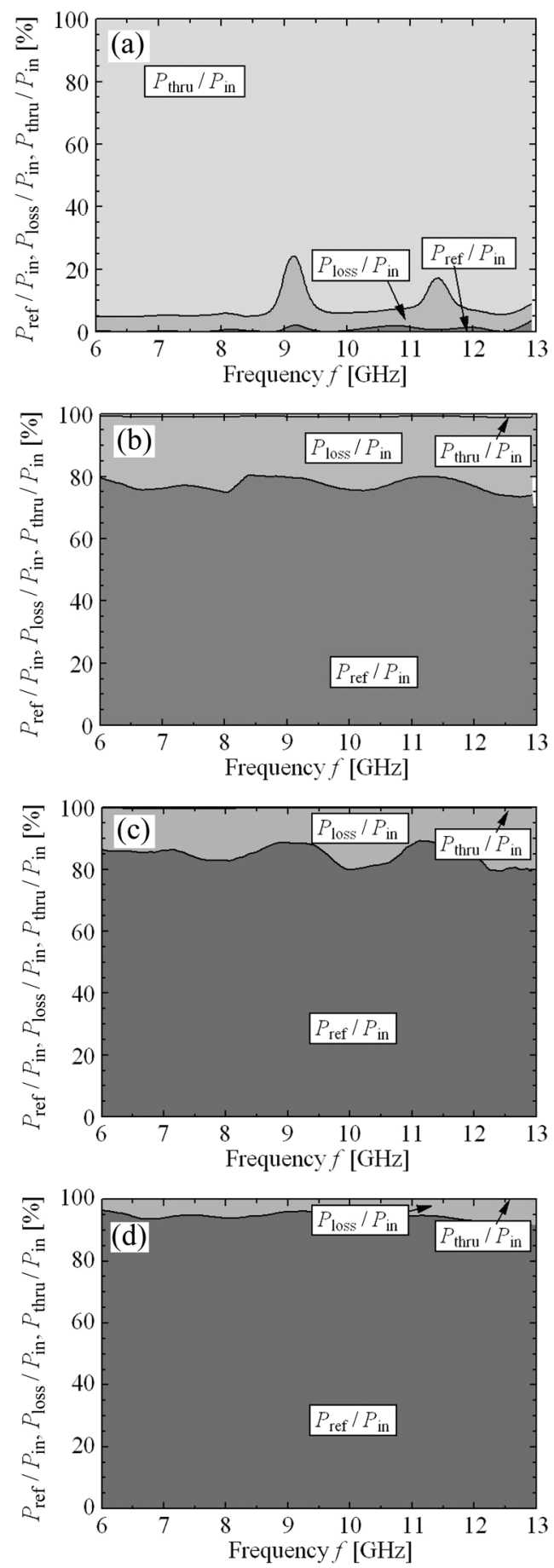

Fig. 4. Frequnecy dependences of $P_{\text {ref }} / P_{\text {in }}, P_{\text {loss }} / P_{\text {in }}, P_{\text {thru }} / P_{\text {in }}$ in (a) the polyester nonwoven textile, (b) the sample $\mathrm{Ni}-P_{\mathrm{M}}$, (c) the sample $\mathrm{Ni}-P_{\mathrm{L}}$, and (d) the sample Ni-B.

\section{Results AND Discussion}

\section{A. Imaginary Part of Permeability in Shielding Textile}

Fig. 3 shows a frequency dependence of the imaginary part of permeability $\mu_{\mathrm{h}}^{\prime \prime}$ measured for the sample Ni-B. In Fig. 3, the imaginary part of permeability $\mu_{\mathrm{h}}^{\prime \prime}$ in the sample Ni-B was about 6 over $1 \mathrm{GHz}$ because of the resonance loss in the Ni-B. The imaginary part of permeability $\mu_{\mathrm{h}}^{\prime \prime}$ in the sample $\mathrm{Ni}-P_{\mathrm{M}}$ 


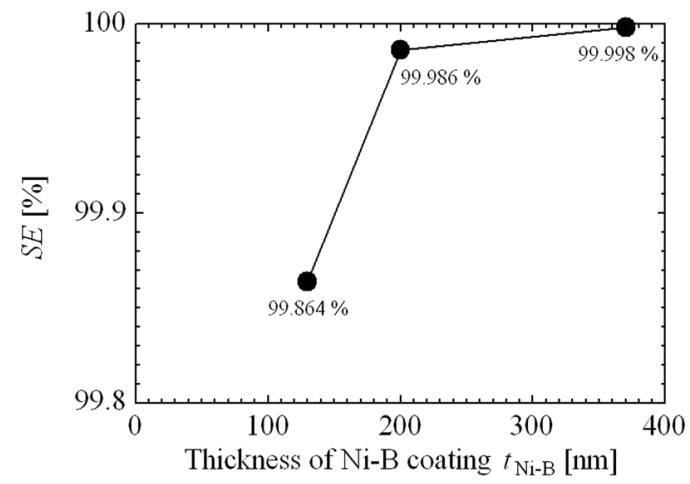

Fig. 5. Relation between the electromagnetic wave shielding effect and the thickness of Ni-B coating on the textile.

and the sample $\mathrm{Ni}-P_{\mathrm{L}}$ disappeared because of the nonmagnetic material.

\section{B. Electromagnetic Wave Shielding Effect}

1) Electromagnetic Wave Shielding Effect of Each Shielding Textile by Electroless Ni-Based Alloy Plating: Fig. 4 shows the frequency dependences of $P_{\text {ref }} / P_{\text {in }}, P_{\text {loss }} / P_{\text {in }}, P_{\text {thru }} / P_{\text {in }}$, where $P_{\text {thru }} / P_{\text {in }}$ means $1-\left(P_{\text {ref }}+P_{\text {loss }}\right) / P_{\text {in }}$ in the polyester nonwoven textile (a), the sample $\mathrm{Ni}-P_{\mathrm{M}}(\mathrm{b})$, the sample $\mathrm{Ni}-P_{\mathrm{L}}$ (c), and the sample Ni-B (d). The thickness of Ni-based alloy coating in all samples was $200 \mathrm{~nm}$.

In Fig. 4(a), SE of the polyester nonwoven textile was about $5 \%$ in the measured frequency band. On the other hand, in Fig. 4(b), SE of the sample Ni- $P_{\mathrm{M}}$ was about $99 \%$ in the measured frequency band, which is higher than SE of the textile with the Ni-Fe coating by sputtering. Because the Ni-P was coated inside the textile, it has a higher EMI shielding effect. In Fig. 4(c), SE of the sample Ni- $P_{\mathrm{L}}$ was about $99.7 \%$ in the measured frequency band, which is higher than that of the sample Ni- $P_{\mathrm{M}}$. Because the conductivity of the sample $\mathrm{Ni}-P_{\mathrm{L}}$ was higher than that of the sample $\mathrm{Ni}-P_{\mathrm{M}}$, the sample $\mathrm{Ni}-P_{\mathrm{L}}$ obtained higher $P_{\text {ref }} / P_{\text {in. }}$ In Fig. 4(d), SE of the sample Ni-B exhibited about $99.98 \%$ in the measured frequency band, and it was the highest in other samples. Because the conductivity of the sample $\mathrm{Ni}-P_{\mathrm{L}}$ was the highest in other samples, it had the imaginary part of permeability $\mu_{\mathrm{h}}^{\prime \prime}$ as described above, so then the sample $\mathrm{Ni}-P_{\mathrm{L}}$ obtained higher SE.

2) Relation Between Electromagnetic Wave Shielding Effect and Thickness of $\mathrm{Ni}-\mathrm{B}$ Coating on Textile: Fig. 5 shows the relation between $\mathrm{SE}$ and the thickness of the Ni-B coating $t_{\mathrm{Ni}-\mathrm{B}}$ on the textile at $10 \mathrm{GHz}$.

In Fig. 5, when increasing the thickness of Ni-B coating $t_{\mathrm{Ni}-\mathrm{B}}$, the SE increased. The electromagnetic wave shielding textile with Ni-B coating showed sufficient reflection and absorbance of the electromagnetic wave.

\section{CONCLUSION}

The electromagnetic wave shielding textile with Ni-based alloy coating was investigated. The results obtained are as follows.

1) The imaginary part of permeability $\mu_{\mathrm{h}}^{\prime \prime}$ in the electromagnetic wave shielding textile with Ni-B coating was about 6 over $1 \mathrm{GHz}$.

2) The SE of the electromagnetic wave shielding textile with $\mathrm{Ni}$-based alloy coating by the electroless plating was over $99 \%$ in the measured frequency band, which is higher than the SE of the textile with the Ni-Fe coating by sputtering.

3) The SE of the electromagnetic wave shielding textile with Ni-B coating exhibited about $99.98 \%$ in the measured frequency band, and it was the highest in other samples.

4) When increasing the thickness of Ni-B coating $t_{\mathrm{Ni}-\mathrm{B}}$, the $\mathrm{SE}$ increased in the electromagnetic wave shielding textile with Ni-B coating.

The textile has an electromagnetic wave shielding ability light, flexible, and breathable properties. The materials for various electromagnetic wave shielding applications are expected with this electromagnetic wave shielding nonwoven textile.

\section{ACKNOWLEDGMENT}

The corresponding author really thanks Mr. Masahiro Tomijima, Mr. Masanori Nakano, and all staff of Kurabo Industries Ltd. He also thanks Mr. Ken-ichi Kudo and Mr. Masayuki Mitsuzawa, Nagano Prefecture General Indistrial Technology Center, and Mr. Kenji Ikeda, Taiyo Yuden Co., Ltd. for assisting the measurement.

\section{REFERENCES}

[1] S. Yoshida, "BUSTERAID, a high-frequency electromagnetic noise suppressor," J. Magn. Soc. Jpn., vol. 22, no. 10, pp. 1353-1356, 1998.

[2] M. Sonehara, T. Sato, M. Takasaki, H. Konishi, Y. Miura, and M. Yamaguchi, "Preparation and characterization of nano-fiber nonwoven textile for electromagnetic wave shielding," IEEE Trans. Magn., vol. 44, no. 11, pp. 3107-3110, Nov. 2008

[3] M. Yamaguchi, Y. Miyazawa, K. Kaminishi, and K.-I. Arai, "A new 1 MHz-9 GHz thin film permeameter using a side-open TEM cell and a planar shielded-loop coil," Trans. Magn. Soc. Jpn., vol. 3, no. 4, pp. 137-140, 2003.

[4] M. Yamaguchi, K.-H. Kim, T. Kuribara, and K.-I. Arai, "Thin film RF noise suppressor integrated in a transmission line," IEEE Trans. Magn., vol. 38, no. 5, pp. 3183-3185, May 2002. 